\title{
A team build-test-redesign project in an engineering statics course
}

\section{Dr. Xiaobin Le P.E., Wentworth Institute of Technology}

Professor, Ph.D, PE., Department of Mechanical Engineering and Technology, Wentworth Institute of Technology, Boston, MA 02115, Phone: 617-989-4223, Email: Lex@ wit.edu, Specialization in Computer Aided Design, Mechanical Design, Finite Element Analysis, Fatigue Design, Solid Mechanics and Engineering Reliability

\section{Prof. Richard L Roberts, Wentworth Institute of Technology}

Associate Professor, Department of Mechanical Engineering College of Engineering and Computer Science Wentworth Institute of Technology 550 Huntington Ave. Boston, MA 02115

\section{Dr. Gloria Guohua Ma, Wentworth Institute of Technology}

Gloria Ma is a Professor in the Department of Mechanical Engineering and Technology. She has been teaching robotics with Lego Mindstorm to ME freshmen for several years. She is actively involved in community services of offering robotics workshops to middle- and high-school girls. Her research interests are dynamics and system modeling, geometry modeling, project based engineering design, and robotics in manufacturing.

Mr. Herb Connors, Wentworth Institute-Dobbs 008 


\title{
A Team Design-Build-Test-Redesign Project in an Engineering Statics Course
}

\begin{abstract}
:
Typically, engineering statics is a lecture-only course without any lab section. Students passively listen to lectures and then do their homework assignments. It is commonly agreed that engineering statics is a difficult and stressful course and we need to motivate students for active learning by different approaches. We have introduced a team design project in our engineering statics course. We not only wanted to motivate students to actively learn statics but also help students get familiar with the process of design projects and to accumulate some hands-on experiences in conducting a design project. This project was to design-build-test-redesign a wooden structure. In this project, students worked in a team, designed, built and tested their first wooden structure. The maximum compressive force was recorded when the wooden structure fractured or lost stability. Students were required to observe and describe the failure of their designs and then redesigned and retested their wooden structures. In the end, they were required to write a technical report. These activities helped them to get familiar with the engineering design process, gain some hands-on experience for conducting a design project, and motivate them to actively study engineering statics.
\end{abstract}

Keywords: Design project, Engineering statics, Tests on the prototype, Failure analysis, Teamwork ability, Wooden structure

\section{Introduction}

One of the primary goals in a mechanical engineering program is that students can conduct a design project. The number one design criteria for a design project is that the product must be safe $^{[1]}$. To know whether a product or a component is safe or not, the first information that mechanical engineers must obtain is its internal forces through engineering statics. Engineering statics is the first technical core course in a sophomore-level engineering curriculum. Teaching and learning engineering statics is a challenge because the concepts of moments, reaction forces, the behavior of different supports, the free-body diagrams, a group of coupling-equations for solving unknown forces, trusses, frames, machines, etc. are abstract and difficult to be appreciated ${ }^{[2,3]}$. Typically, the engineering statics course is treated as a gatekeeper for a mechanical engineering program ${ }^{[4,5]}$.

Typically, engineering statics is a lecture-only course without any lab section. Students passively listen to lectures and then do their homework assignments. It is commonly agreed that it is a difficult and stressful course and we need to motivate students for active learning using different approaches. There are lots of approaches for motivating students to actively learn statics such as a flipped classroom, visual demonstrations, working on examples together ${ }^{[6,7,8,9]}$. Another popular approach is to include some hands-on activities in the engineering statics course [9,10,11]. The design experience is very important in all technical areas. Recent trends have 
pushed design experiences as early in the curriculum as possible. Design projects have been widely used for facilitating students to effectively study engineering statics ${ }^{[2,3,12,13,14]}$.

We introduced a team design project in our engineering statics course. We wanted not only to motivate students to actively learn statics through a hands-on design project but also to help students get familiar with the engineering design process. This paper describes this team design project, its implementation, and presents some samples of the design projects constructed by students and test results. The paper also presents survey data analysis and some discussions. Based on the students' surveys and direct observations, students gained hands-on experience from this team project and had a better understanding of engineering statics.

\section{The design-build-test-redesign wooden structure project}

What kind of design project is suitable for this sophomore-level engineering statics? We will first briefly describe the structure of our engineering statics course and then explain in detail the design-test-redesign project in this course.

\subsection{Developing a design project for the course of engineering statics}

The engineering statics course is a required core four-credits lecture-only technical course during a fifteen-week semester. Before this course, students have learned several basic courses related to mechanical engineering. In the course of computer-aided design and manufacturing (CAD/CAM), they are introduced to several fundamental manufacturing processes for manufacturing components. Students learn to build 3D models in SolidWorks and create component drawings and assembly drawings in an engineering graphics course. Students learn the general engineering design process through successful design cases in an introduction to engineering design course, they also understand safety is one of the key criteria in design through various engineering failures/disaster design cases. After the engineering statics course, the next core technical course is the mechanics of materials in the design thread, where mechanical students can start to design a safe component according to a required factor of safety. All the above-mentioned courses have a lab except for engineering statics.

Since engineering statics doesn't have a lab component, the design project could not be very complicated and could not require heavy machining work. Students cannot design a safe component because they haven't learned the mechanics of materials yet. Therefore the design project cannot include a dimensional design. However, they have learned the engineering design process $^{[1]}$ and applied the process to several design projects in their introduction to engineering design course. After discussions, we believe that the design project should contain the following items: (1) There must be some construction, but construction tasks can not be too complicated; (2) The design project must be directly related to one of the applications of engineering statics so that they can use the knowledge learned in lecture to analyze their designs; (3) The design project must include testing on the prototype and failure analysis from the testing. (4) Redesigning of the prototype based on their failure analysis; (5) The design project will be a team project so that students will work together as a team outside of lectures.

The textbook we used for the engineering statics was "Engineering Statics" by R. C. Hibbeler. In this textbook, the applications of the concepts and principles of engineering statics are on trusses, beams, frames, and machinery ${ }^{[15]}$. For easy-construction, we choose a wooden structure 
as the object of the design project. Since the dimension design was not part of the design project, we chose commercially available popsicle-sticks as the material for the wooden structure. This could make the construction of the wooden structure simple since students haven't learned the concepts of stress, material strength, and factor of safety. Compression testing on the wooden structure was used to judge the quality of the constructed wooden structure and to provide necessary failure information for redesigning the wooden structure. So, the design project for engineering statics was to design-build-test-redesign a wooden structure.

\subsection{The design-build-test-redesign wooden structure project}

Three main objectives of the design-build-test-redesign wooden structure project were: (1) Create hands-on activities which could help students to have a better understanding of engineering statics; (2) Students can get more familiar with the engineering design process and accumulate some hands-on experience through this design project, and (3) Students will gain some team-work ability through conducting a design project.

We successfully implemented this design-build-test-redesign wooden structure project in the course of engineering statics. The summary description of the project implemented during the 2019 Fall semester is as the following.

\section{Restraints and conditions:}

- This will be a team design project with two to three team members.

- Only twenty-five popsicle sticks will be used to design and construct a wooden structure of 12 inches long and 3 inches high (no width restrictions). The provided popsicle sticks as shown in Figure 1 are commercially available for purchase. The nominal dimensions of the popsicle sticks are 4-1/2" (L) x 3/8" (T) x 1/12" (W).

- Any type of glue may be used to hold the pop-sticks together. The sticks may be cut and or fabricated in any way. No other material or additional wood may be used.

\section{Testing procedure and conditions:}

- The wooden structure was tested on an Instron Universal Test Machine as shown in Figure 2. The flat-thick steel plate with a diameter 6.5" was attached to the upper arm of the Instron machine and was slowly moved down at a speed 0.01 " per second which was controlled by a test method. The wooden structure was supported by a support fixture which was a two-rods with a diameter 1 " and located 11 inches apart.

\section{Evaluation criteria:}

- During testing, the wooden structure was sandwiched between the top plate and the bottom two-rods support fixture and was under a compressive force. The maximum compression load was automatically recorded when the wooden structure under test lost its stability or some truss members fractured. The design goal of the wooden structure was to obtain the maximum compression load. 


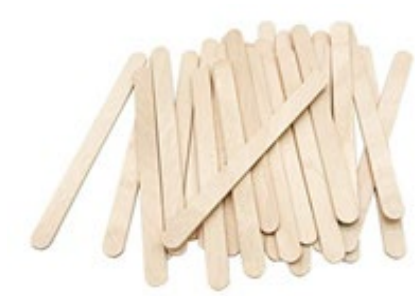

Figure 1 The 4-1/2" (L)x 3/8" (T) x $1 / 12$ " (W) popsicle sticks for the class project

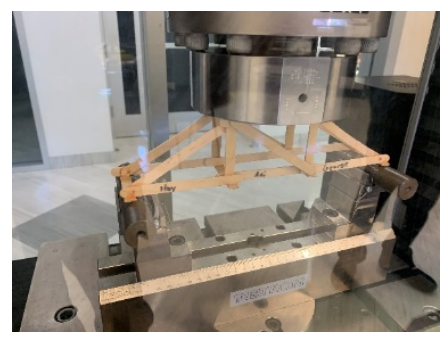

Figure 2 The settings for a wooden structure test

\section{Required activities:}

- The design-build-test-redesign wooden structure project was released in week \#8 when the topics of trusses, structures, frames, and machines were discussed during lectures. The first testing on the wooden structure was during week \#11 and the second testing was during week \#13. Each team was required to have one one-hour team meeting per week outside of lecture hours.

- Teams were required to use the knowledge and force analysis skills from lectures to design their best wooden structure with the supplied twenty-five popsicle sticks.

- Teams were required to observe the failure, conduct the failure analysis and redesign the wooden structure for the second round of tests.

- Teams were required to write a technical report about the design-build-test-redesign wooden structure project at the end of the course.

\section{Implementation and test data analysis}

From week \#8 in the Fall semester 2019, we started lecturing about trusses, frames, machines, and beams. In that week, the design-build-test-redesign wooden structure project was released, and students were asked to form their teams with two to three team members. The restraints \& conditions, testing procedure $\&$ conditions and evaluating criteria of the design projects were explained and discussed during lectures. They had approximately 3 weeks to apply the concepts and principles of force analysis on a truss and a frame to generate some conceptual designs and then to pick the best one for constructing a wooden structure. The first wooden structures were tested during week \#11. One lecture was used to run the wooden structure test and to run the failure analysis. Each team was asked to observe the failures of their and other wooden structures during testing. In the next two weeks, they were asked to redesign and to construct their second wooden structure based on the failure information obtained on the first round testing. During week \#13, another lecture was used to run the second wooden structure testing and the failure analysis. At the end of the semester, teams were required to write and submit a technical report.

\subsection{Examples of some wooden structures}

The design team presented quite different wooden structures for their first testing in week \#11. Example 1 as shown in Figure 3 was quite normal and had a relatively larger compressive load. But the example 2 as shown in Figure 4 was a kind of weak wooden structure although it did satisfy the restraints and testing conditions. 


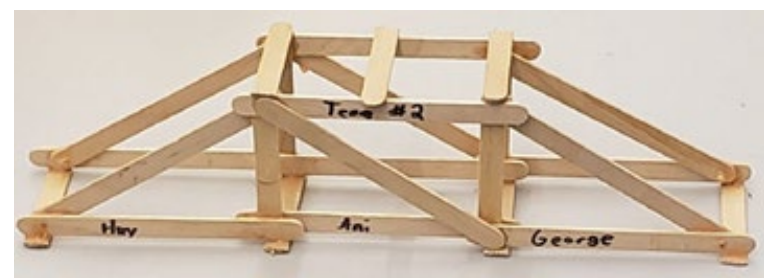

Figure 4 Example 1 of a wooden structure

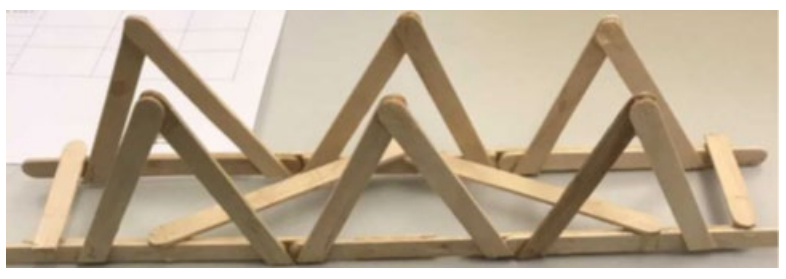

Figure 4 Example 2 of a wooden structure

\subsection{Testing, failure analysis, and redesign}

In week \#11, the first round testing was performed. Students not only see each other's designs but also observe the failures of each design under testing. After all the testing, they analyzed the failure of their wooden structure.

Design teams significantly benefited from the testing and failure analysis. They summarized the three failure modes observed from the testing: (1) the failure on the glued joints because the type of glue was not good for wooden materials, (2) the fracture of buckling popsicles-sticks due to compression as shown in Figure 5, and (3) the failure due to uneven contacting points as shown in Figure 6.

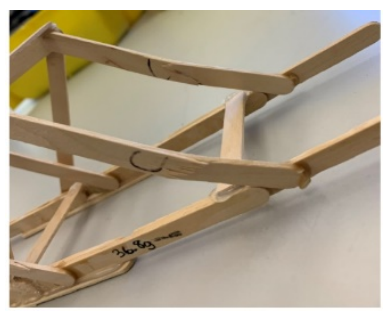

Figure 5 The fractures of the buckling popsicle-sticks due to compression

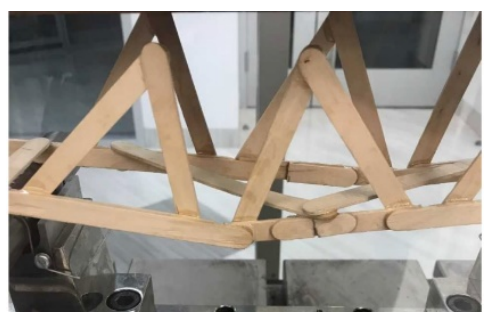

Figure 6 The failure mode due to uneven contacting points

During week \#11 to week \#13, the design teams redesigned their wooden structures based on the information obtained through the failure analysis of the first testing. Some teams did not improve their redesigned structures, but several teams did significantly improve their design. Figure 7 shows one improved wooden structure. The failure of the first wooden structure was due to the fractures of the buckling popsicle-sticks as shown in Figure 7 a). The improved wooden structure was done by gluing additional popsicle-sticks on the weak members as shown in Figure 7 b).

Another improved wooden structure is displayed in Figure 8. The failure of the first wooden structure was due to fracture of the buckling popsicles-sticks as shown in Figure $8 \mathrm{a}$ ). The improved wooden structure was to add a transverse popsicle-stick to reduce the buckling as shown in Figure 8 b). In both cases, the maximum compression load increased significantly. 


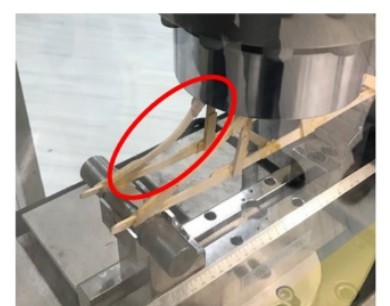

a) The first wooden structure

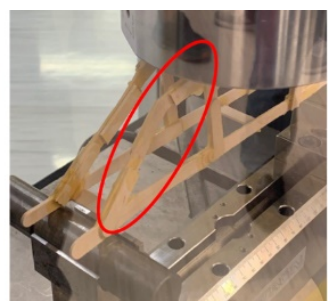

b) The improved wooden structure

Figure 7 The improved wooden structure 1

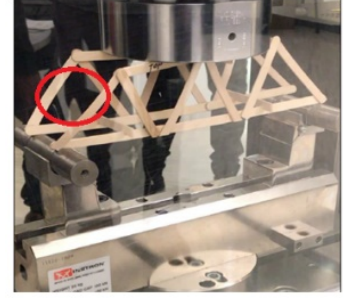

a) The first wooden structure

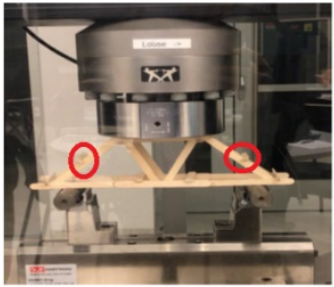

b) The improved wooden structure

Figure 8 The improved wooden structure 2

\subsection{Test results and data analysis}

The test results of the wooden structure are listed in Table 1. According to the t-test, the average maximum compression load of the second testing on the wooden structures was statistically significantly larger than the average maximum compression load of the first testing on the wooden structures. So, the redesigned wooden structures were significantly improved through testing and failure analysis. But not all the redesigned wooden structures were improved. From Table 1, two out of six design teams had less maximum compression loads on their second redesigned wooden structures.

Table 1 The maximum compassion loads of two testing

\begin{tabular}{|c|c|c|c|c|c|c|c|c|}
\hline & $\begin{array}{c}\text { Team } \\
\# 1\end{array}$ & $\begin{array}{c}\text { Team } \\
\# 2\end{array}$ & $\begin{array}{c}\text { Team } \\
\# 3\end{array}$ & $\begin{array}{c}\text { Team } \\
\# 4\end{array}$ & $\begin{array}{c}\text { Team } \\
\# 5\end{array}$ & $\begin{array}{c}\text { Team } \\
\# 6\end{array}$ & Average & Standard deviation \\
\hline The first test & 29 & 98 & 35 & 36 & 24 & 88 & 51.67 & 32.46 \\
\hline The second test & 128.4 & 86 & 62 & 90.9 & 72.2 & 65.2 & 84.2 & 24.51 \\
\hline
\end{tabular}

Other sections of engineering statics in our mechanical engineering program in Fall 2019 also had a similar wooden structure design project. They also used only twenty-five popsicle-sticks to build the wooden structure with the same testing condition. But each student was asked to complete one wooden structure individually and run only one test. The test results of 36 wooden structures and their average \& standard deviation are listed in Table 2. According to the t-test, the average maximum compression load of the wooden structures in Table 2 was not statistically different from the average maximum compression load of the first testing of wooden structures.

Table 2 The maximum compression load of the wooden structures in other sections

\begin{tabular}{|r|l|l|l|}
\hline $\begin{array}{l}\text { The maximum compression } \\
\text { load (lbs) }\end{array}$ & \multicolumn{4}{|l|}{$57.15 ; 68.57 ; 48.53 ; 17.26 ; 40.87 ; 43.21 ; 24.24 ; 36.00 ; 22.89 ; 32.75 ;$} \\
\hline & $111.22 ; 39.83 ; 58.22 ; 25.99 ; 35.37 ; 10.14 ; 84.63 ;$ \\
\hline Average & 44.52 & Standard deviation & 24.83 \\
\hline
\end{tabular}

The test data analysis shows that the quality of wooden structures designed by an individual and by a design team did not have a statistically significant difference at their first design. But, the 
quality of the redesigned wooden structures based on actual testing and its failure analysis was statistically significantly improved.

\section{Discussions and conclusions}

\subsection{Class survey data analysis and discussions}

A class survey about the design-build-test-redesign wooden structure project was conducted at the end of the engineering statics course. The class had 17 students with 13 male students and 4 female students. We successfully collected 16 surveys.

The survey results of question \#1 are listed in Table 3. 100\% of students agreed that the design project should be kept for the future class of this engineering statics. The direct observation and feedback through conversation with students clearly shown that students wanted to have some hands-on activities on this lecturing-only course.

Table 3 The survey results of the survey question \#1

\begin{tabular}{|c|c|c|c|c|c|c|}
\hline \multicolumn{7}{|c|}{$\begin{array}{l}\text { Survey question \#1: I like the design-build-test-redesign wooden structure project and believe that it should } \\
\text { continuously be a part of the MECH2000-Engineering Statics course. }\end{array}$} \\
\hline Choices & strongly agree & agree & no opinion & disagree & strongly disagree & Total \\
\hline Results & 10 & 6 & 0 & 0 & 0 & 16 \\
\hline Percentage $\%$ & $62.5 \%$ & $37.5 \%$ & $0 \%$ & $0 \%$ & $0 \%$ & \\
\hline
\end{tabular}

The survey results of question \#2 are listed in Table 4. 100\% of students strongly agreed or agreed that the project helps them to have a better understanding of engineering statics. After the design project was released, the interactions and questions between the faculty and students, during office visits for this course were significantly increased. There were active discussions about how to build wooden structures and how to analyze the forces of the wooden structures. These also proved that the design project did motivate students to learn engineering statics.

Table 4 The survey results of the survey question \#2

\begin{tabular}{|c|c|c|c|c|c|c|}
\hline \multicolumn{7}{|c|}{$\begin{array}{l}\text { Survey question \#2: The design-build-test-redesign wooden structure project helps me to have a better } \\
\text { understanding of Engineering Statics. }\end{array}$} \\
\hline Choices & strongly agree & agree & no opinion & disagree & strongly disagree & Total \\
\hline Results & 6 & 10 & 0 & 0 & 0 & 16 \\
\hline Percentage $\%$ & $37.5 \%$ & $62.5 \%$ & $0 \%$ & $0 \%$ & $0 \%$ & \\
\hline
\end{tabular}

The survey results of question \#3 are listed in Table 5. $87.5 \%$ of students strongly agreed or agreed that the project helps them to build team-work ability.

Table 5 The survey results of the survey question \#3

\begin{tabular}{|c|c|c|c|c|c|c|}
\hline \multicolumn{6}{|c|}{ Survey question $\# 3$ : The design-build-test-redesign wooden structure project helps me to build team-work ability. } \\
\hline Choices & strongly agree & agree & no opinion & disagree & strongly disagree & Total \\
\hline Results & 6 & 8 & 2 & 0 & 0 & 16 \\
\hline Percentage $\%$ & $37.5 \%$ & $50 \%$ & $12.5 \%$ & $0 \%$ & $0 \%$ & \\
\hline
\end{tabular}

The survey results of question \#4 are listed in Table 6. 93.75\% of students strongly agreed or agreed that the project helps them to get familiar with the process of a design project and accumulate hands-on experience of conducting design projects. Project technical reports and feedback from the conversation with some students have shown that this design project significantly helped them to have a much better understanding of the restrains and conditions for design projects. The students said that they greatly benefited from the testing and failure 
analysis. The majority of groups redesigned and did improve the wooden structures by using the information from the failure analysis.

Table 6 The survey results of the survey question \#4

\begin{tabular}{|c|c|c|c|c|c|c|}
\hline \multicolumn{7}{|c|}{$\begin{array}{l}\text { Survey question \#4: The design-build-test-redesign wooden structure project helps me to get familiar with the } \\
\text { process of a design project and cumulate hands-on experience of conducting a design project. }\end{array}$} \\
\hline Choices & strongly agree & agree & no opinion & disagree & strongly disagree & Total \\
\hline Results & 8 & 7 & 1 & 0 & 0 & 16 \\
\hline Percentage \% & $50 \%$ & $43.75 \%$ & $6.25 \%$ & $0 \%$ & $0 \%$ & \\
\hline
\end{tabular}

\subsection{Summary and conclusions}

Engineering statics is the first core technical course in our mechanical engineering program and is typically a lecture-only course without any lab section. Some hands-on activities should be included for motivating students to learn the topics. Even though students attending this course are not able to conduct dimension design based on load because they haven't studied mechanics of materials, a proper team design project still can be included in this course to motivate them to learn engineering statics and to accumulate some hands-on real design experience. The designbuild-test-redesign wooden structure project described in this paper is one of the proper team design projects because this project has the following three features:

- The restraints and evaluation conditions are specified and easy to understand. This will help the design team to conduct their conceptual design. It is suitable for sophomore students who have little design experience.

- The wooden structures are constructed by the provided twenty-five popsicle-sticks. The popsicle-sticks are joined by any type of glue. So, it is easy to build and is suitable for the course without any lab section.

- The wooden structures are directly evaluated by testing. The failure modes can be directly recorded and observed. The failure analysis can guide them to redesign their wooden structure. The evaluation through testing on the prototype in this project replaces the dimension design based on loading for these sophomore students.

The implementation of the design-build-test-redesign wooden structure project in the Fall semester of 2019 was very successful. Based on the class survey, direct observation and feedback through conversations with students, the followings are some summaries and conclusions.

- The design-build-test-redesign wooden structure project was a good design project for engineering statics. 100 percent of students liked it and suggested that it will be kept for the future class of this course.

- The design-build-test-redesign wooden structure project significantly increased the interaction, questions, and office visits for this course. $100 \%$ of students strongly agreed or agreed that the project helps them to have a better understanding of engineering statics.

- The design teams scheduled a one-hour weekly meeting where they discussed the restraints and testing conditions, conducted the conceptual design and built wooden structures. The majority $(87.5 \%)$ of students strongly agreed or agreed that the project helped them to build teamwork ability. 
- Students felt excited to test their prototypes, observe the failure modes and conduct the failure analysis. Furthermore, students had the opportunity to redesign their wooden structures and retest it again. This was the first time that they could build an object, test it, redesign it and then re-test it. $93.75 \%$ of students strongly agreed or agreed that the project helps them to get familiar with a process of the design project and cumulate hands-on experience of conducting a design project.

Even though this project significantly increased the interaction, questions, and office visits for this course, we noticed that the class final grades of the students in Fall 2019 who participated in this team design-build-test-redesign project weren't significantly increased when compared with the previous class final grades of students who did not participate in such a team deign-buildtest-redesign project.

\section{References}

[1]. Voland, G., "Engineering by Design", Second edition, Pearson Prentice Hall, 2004

[2]. Pike, D. M. (1996, June), Design And Test Project In A Statics Course Paper presented at 1996 Annual Conference, Washington, District of Columbia.

[3]. Van, D. (2004, June), Designing A Mechanical Breadboard For Effective Teaching Of Engineering Statics, Paper presented at 2004 Annual Conference, Salt Lake City, Utah.

[4]. Brake, N. A., \& Adam, F. A. (2016, June), Integrating a 3-D Printer and a Truss Optimization Project in Statics, Paper presented at 2016 ASEE Annual Conference \& Exposition, New Orleans, Louisiana.

[5]. Wingate, K. A., \& Ferri, A. A., \& Feigh, K. M. (2018, June), The Impact of the Physics, Statics, and Mechanics Sequence on Student Retention and Performance in Mechanical Engineering, Paper presented at 2018 ASEE Annual Conference \& Exposition, Salt Lake City, Utah.

[6]. Holdhusen, M. H. (2015, June), A "Flipped" Statics Classroom, Paper presented at 2015 ASEE Annual Conference \& Exposition, Seattle, Washington.

[7]. Le, X., \& Roberts, R. L., \& Moazed, A. R., \& Duva, A. W. (2012, June), Applications of SolidWorks in Teaching Courses of Statics and Strength of Materials, Paper presented at 2012 ASEE Annual Conference \& Exposition, San Antonio, Texas.

[8]. Powell, O., \& Richards, M., \& Jensen, D. D., \& Brown, N. M. (2014, June), Increasing Conceptual Understanding in an Engineering Core Course using a Statics Visualization Program Paper presented at 2014 ASEE Annual Conference \& Exposition, Indianapolis, Indiana.

[9]. Kim, K., \& Rezaei, A., \& Shih, A., \& Jawaharlal, M., \& Shelton, M. (2007, June), Development Of Online Hands-On Experiments For Hybrid Vector Statics Courses, Paper presented at 2007 Annual Conference \& Exposition, Honolulu, Hawaii.

[10]. Davishahl, E., \& Pearce, R., \& Haskell, T. R., \& Clarks, K. J. (2018, June), Statics Modeling Kit: HandsOn Learning in the Flipped Classroom, Paper presented at 2018 ASEE Annual Conference \& Exposition, Salt Lake City, Utah.

[11]. Anderson, M. (2012, June), A Design-by-Analysis Project for Introductory Students in Aerospace Engineering, Paper presented at 2012 ASEE Annual Conference \& Exposition, San Antonio, Texas.

[12]. Liu, S. (2014, June), Implementing Project-Based Learning in Physics and Statics Courses, Paper presented at the 2014 ASEE Annual Conference \& Exposition, Indianapolis, Indiana.

[13]. Chang, G., \& Peterson, W. (2009, June), Bridge Design Project: A Hands-On Approach To Statics And Strength Of Materials Learning, Paper presented at 2009 Annual Conference \& Exposition, Austin, Texas.

[14]. Kou, Z., \& Mehta, S. (2005, June), Research In Statics Education - Do Active, Collaborative, And ProjectBased Learning Methods Enhance Student Engagement, Understanding, And Passing Rate? Paper presented at 2005 Annual Conference, Portland, Oregon.

[15]. Hibbeler, R. C., Engineering Mechanics (Statics), 14th Edition, Prentice Hall 2016. 